\title{
Doença renal crônica: relação dos pacientes com a hemodiálise
}

\author{
Chronic kidney disease: relation of patients with hemodialysis
}

Bianca Pozza dos Santos ${ }^{1}$, Vanessa Athaydes Oliveira², Marilu Correa Soares ${ }^{1}$, Eda Schwartz ${ }^{1}$

${ }^{1}$ Programa de Pós-Graduação em Enfermagem, Universidade Federal de Pelotas (UFPel) - Pelotas (RS), Brasil.

${ }^{2}$ Faculdade de Enfermagem, UFPel - Pelotas (RS), Brasil.

DOI: http://dx.doi.org/10.7322/abcshs.v42i1.943

\section{RESUMO}

Introdução: Quando há perda das funções reguladora, excretora e endócrina dos rins pode ocorrer doença renal crônica, que é uma doença lenta e silenciosa. Quando se perde totalmente a função renal, adotam-se as Terapias Renais Substitutivas, como a hemodiálise. Objetivo: Conhecer a relação dos pacientes renais crônicos com a hemodiálise. Métodos: Estudo qualitativo, exploratório e descritivo, realizado com seis pacientes em hemodiálise. A coleta de dados ocorreu entre abril e maio de 2012, e foi realizada por meio de entrevista semiestruturada, gravada em mídia digital e, posteriormente, transcrita na íntegra. Para a análise dos dados, seguiram-se os passos da proposta operativa de Minayo (pré-análise, exploração do material, tratamento dos resultados obtidos e interpretação). A pesquisa foi aprovada sob o número 36/2012 pelo Comitê de Ética em Pesquisa. Resultados: Emergiram as categorias "instalação da doença renal crônica", "relação com a máquina de hemodiálise", "quando faz a hemodiálise e a alteração da aparência física", "orientação sobre o cuidado à saúde e o autocuidado". Conclusão: Após a descoberta do diagnóstico da doença renal crônica e a necessidade da hemodiálise, os pacientes passam por um processo de rejeição e de aceitação, que pode interferir no seu estado emocional e psicológico, acarretando consequências no enfrentamento da doença e do tratamento.

Palavras-chave: doença crônica; insuficiência renal crônica; diálise renal; adaptação psicológica.

\begin{abstract}
Introduction: When kidneys lose regulatory, excretory and endocrine functions, chronic kidney disease may arrive, a slow and silent disease. When renal function is completely lost, Renal Replacement Therapies are adopted, such as hemodialysis. Objective: To know the relationship of renal chronic patients with the hemodialysis. Methods: Qualitative, exploratory and descriptive study accomplished with six patients on hemodialysis. The data collection occurred between April and May 2012 and was performed by means of semi structured interviews, being recorded in digital media and, later, transcribed in full. For the analyze data, the steps of the operative proposal of Minayo (pre-analysis, material exploration, processing of results and interpretation) were followed. The study was approved under number 36/2012 by the Research Ethics Committee. Results: Emerged the categories "installation of chronic kidney disease", "relation with the hemodialysis machine", "when the hemodialysis is done and the alteration of the physical appearance", "guidance on the health care and the self-care". Conclusion: After the discovery of the diagnosis of chronic kidney disease and the need of the hemodialysis, the patients go through a process of rejection and acceptance, which can interfere intheir emotional and psychological conditions, causing consequences in facing the disease and the treatment.
\end{abstract}

Keywords: chronic disease; renal insufficiency, chronic; renal dialysis; adaptation, psychological. 


\section{INTRODUÇÃO}

Os rins são órgãos essenciais à manutenção da homeostase do corpo humano. Eles desempenham função vital, pois são responsáveis pela eliminação de toxinas, pela regulação do volume de líquidos e pela filtragem do sangue (filtram, por minuto, cerca de $20 \%$ do volume sanguíneo bombeado pelo coração $)^{1,2}$. Nesse sentido, a função renal é avaliada pela filtração glomerular (FG) e sua diminuição é observada na Doença Renal Crônica (DRC), quando há perda das funções reguladora, excretora e endócrina do rim. Quando a FG atinge valores inferiores a $15 \mathrm{~L} / \mathrm{min} / 1,73 \mathrm{~m}^{2}$, estabelece-se a falência funcional renal (FFR), comprometendo os demais órgãos ${ }^{1}$.

A progressão da doença renal é lenta, silenciosa, e o organismo consegue se adaptar até nas suas fases mais avançadas. No último estágio, denominado fase pré-diálise, os primeiros sintomas começam a surgir e as análises laboratoriais evidenciam a existência de alterações. O paciente apresenta níveis elevados de fósforo, de potássio e de paratormônio, além de anemia, acidose, emagrecimento, sinais de desnutrição, hipertensão, enfraquecimento ósseo, cansaço, diminuição da libido e do apetite. Também perde massa muscular e gordura, mas com a retenção de líquidos pode não se notar o emagrecimento, pois o peso se manterá igual ou aumentará em virtude do edema, que inclusive poderá estar presente nos membros inferiores ${ }^{3}$.

$\mathrm{Na}$ fase inicial da FFR, as principais medidas terapêuticas adotadas são o controle da hipertensão arterial e a ingestão restrita de proteínas. Com o avanço da falência renal, o tratamento é medicamentoso, variando de acordo com as complicações e com as comorbidades apresentadas pelo paciente ${ }^{4}$. Já quando se perde totalmente a função renal, são adotadas as Terapias Renais Substitutivas (TRS).

Nas TRS, a diálise é empregada para remover líquidos e produtos residuais urêmicos do organismo quando o corpo não consegue mais fazê- $-\mathrm{lo}^{2}$. Esse fato requer adaptação ou, pelo menos, adesão do paciente ao tratamento dialítico, visto que muitas pessoas não conseguem se adaptar ao novo estilo de vida, mas apenas o aderem por ser fundamental para a manutenção da vida ${ }^{5}$.

Dos métodos de terapia dialítica, a hemodiálise é a mais utilizada, implantada no Brasil desde a década de 19502,6. Trata-se de um processo impulsionado por difusão para depuração de solutos relativamente pequenos, como os eletrólitos e a ureia. Os principais componentes do sistema hemodialítico são o rim artificial ou o dialisador, em que os respectivos dispositivos mecânicos bombeiam o sangue do paciente e o dialisado (líquido de composição química específica, usado para a realização da hemodiálise $)^{2}$.

Quando o paciente realiza esse tratamento, deve comparecer três vezes por semana a um serviço especializado de nefrologia, durante um período que pode variar de três a cinco horas. $\mathrm{O}$ tempo que terá de se dedicar à hemodiálise é longo, já que, além das horas na máquina, muitas vezes é preciso percorrer longas distâncias até o hospital ou até a clínica onde as sessões são realizadas.
Esse tempo e o declínio de sua capacidade física impõem o afastamento de boa parte de suas atividades cotidianas ${ }^{3}$.

O paciente convive com os percalços acometidos pela DRC, uma vez que é uma doença que ocasiona situações estressantes, mudanças no estilo de vida, diminuição da energia física, alteração da aparência pessoal e novas incumbências. Situações que exigem o estabelecimento de estratégias de enfrentamento para aderir às novas condições de vida ${ }^{5}$.

O novo estilo de vida a ser adotado pela pessoa submetida à hemodiálise pode originar sentimentos como medo, ansiedade, insegurança, culpa e raiva. Como consequência, há a probabilidade de uma diminuição da autoestima e de um comportamento de resistência em seguir o tratamento adequadamente, prejudicando, assim, o quadro clínico ${ }^{7}$.

A experiência do tratamento hemodialítico e a dependência da máquina podem gerar sofrimento e angústia, pois a hemodiálise é um tratamento doloroso, monótono e limitado. Todavia, torna-se indispensável para a manutenção da vida, uma vez que limpa e filtra o sangue, controla a pressão arterial e ajuda a manter o equilíbrio de substâncias químicas, como o sódio e o potássio. Geralmente, a queixa mais frequente entre os pacientes é o vínculo obrigatório a ser construído com a máquina, sendo condição vital para a manutenção da vida ${ }^{8}$.

Inclusive, um estudo realizado com 15 pacientes em tratamento pré-dialítico apresentou que a necessidade futura da hemodiálise, em virtude da progressão da doença renal, leva a sentimentos de receio relacionados à morte de pessoas conhecidas que realizaram essa terapia. Além do mais, "ficar presa a uma máquina” e "entrar na máquina" repercutem a perda da liberdade ${ }^{9}$.

Baseado nesse contexto salienta-se que a dependência da hemodiálise é uma experiência negativa, tanto fisiologicamente como emocionalmente, pois faz com que o paciente não consiga esquecer sua condição crônica de saúde, lembrando que a sua vida depende de uma máquina. Com isso, o medo da morte e o futuro incerto acabam aparecendo como consequência da doença e do tratamento.

Assim, torna-se importante o trabalho formado por uma equipe composta de médicos, enfermeiros, nutricionistas, assistentes sociais, psicólogos, técnicos de enfermagem e profissionais envolvidos na manutenção dos equipamentos, de modo a garantir a saúde e o bem-estar dos pacientes ${ }^{10}$. Ainda, se faz necessário que a equipe identifique como essa problemática afeta a vida de uma pessoa e conheça os significados atribuídos à doença e à hemodiálise ${ }^{9}$. Baseado nesse contexto, este estudo teve como objetivo conhecer a relação dos pacientes renais crônicos com a hemodiálise.

\section{MÉTODOS}

Trata-se de um estudo qualitativo e descritivo. A coleta de dados foi realizada entre abril e maio de 2012, em um Serviço de Nefrologia de um hospital regional de grande porte, localizado na região sul do Brasil, e no domicílio das pessoas (com diagnóstico 
de DRC) entrevistadas. Os critérios de inclusão para a participação foram: período de realização da hemodiálise, a pelo menos, um ano; idade igual ou superior a 18 anos; ser capaz de se comunicar verbalmente; concordar com a gravação da entrevista e com a divulgação dos resultados em meio acadêmico e científico.

O número de participantes foi constituído de seis pacientes em tratamento hemodialítico. A definição numérica para a amostra foi definida pelo critério de saturação, ou seja, quando a opinião sobre o assunto começou a ter similaridade de apresentação, além de corresponder ao objetivo do estudo. Assim, a coleta de novos dados supostamente não acrescentaria ou acrescentaria poucos elementos para a discussão em relação à densidade teórica obtida ${ }^{11}$.

Para a coleta de dados, os pacientes foram abordados no serviço e convidados a participar do estudo. Os objetivos da pesquisa foram apresentados por meio do Termo de Consentimento Livre e Esclarecido. Na concordância em participar do estudo, foram agendados local e horário em comum acordo entre o participante e o pesquisador para a realização de entrevista semiestruturada que foi gravada em mídia digital e, posteriormente, transcrita na íntegra.

Após a coleta de dados, o conteúdo das entrevistas foi submetido à leitura exaustiva e foram realizadas codificações e agregações aos núcleos, de acordo com a operacionalização da análise temática, que possui como finalidade encontrar os núcleos de sentido que compõem uma comunicação, cuja frequência pode significar interpretações para o estudo. As fases que se seguiram foram: pré-análise, exploração do material, tratamento dos resultados obtidos e interpretação ${ }^{12}$.

O estudo seguiu os princípios da Resolução n 196/96 do Conselho Nacional de Saúde do Ministério da Saúde, vigente na época ${ }^{13}$, além do Código de Ética dos Profissionais de Enfermagem ${ }^{14}$. Ainda, foi encaminhado ao Comitê de Ética e recebeu aprovação por meio do parecer $n^{\circ} 36 / 2012$. Para manter o anonimato, os participantes foram identificados pela letra " $E$ ", seguido do número arábico conforme a sequência da entrevista e da idade.

\section{RESULTADOS}

As categorias emergidas a partir da análise dos dados foram: "A instalação da doença renal crônica"; "A relação com a máquina de hemodiálise"; "A alteração da aparência física quando é feita a hemodiálise"; "Orientação sobre o cuidado à saúde e o autocuidado".

\section{A instalação da doença renal crônica}

Nesta categoria, os entrevistados relataram como a DRC surgiu, com diferentes abordagens que indicam a sua manifestação. Destacaram-se doenças de base como hipertensão arterial e lúpus eritematoso sistêmico, como afirmado pelo Entrevistado 1 (E1, 39 anos):

Desde 2003, eu tenho problema de insuficiência renal [...]. Eu acho que é a pressão alta, mas eu tenho o diagnóstico de lúpus desde 2003.
Já os entrevistados E2, E3 e E6 abordaram a presença de sinais e sintomas que possam ter sido os primeiros indícios do desenvolvimento da doença renal, progredindo para a cronicidade. Ademais, a fala de E6 apresenta a possível postergação na procura por um atendimento especializado, conforme conduta médica.

Eu estava com muita dor nas costas e fui no médico e ele me deu uma injeção que me fez muito mal. No outro dia tinha que tomar outra, eu entrei em coma por 17 dias [...], depois voltei, mas voltei sem os rins. (E2, 66 anos)

Eu tinha uma baita barriga, todo mundo pensava que eu estava grávida, mas não era gravidez, eu tinha uma febre [...]. Eu fiquei uns três ou quatro meses em cima de uma cama [...]. Aí foi que ele [marido] me levou no médico [...]. Daí o médico disse: vai ter que levar ela para [nome da cidade] urgente [...], os rins pararam, não está funcionando, por isso que ela está com esse barrigão e a pressão dela está muito alta [...]. (E3, 49 anos)

[...] comecei a perder peso, tinha uma sede horrorosa, só tinha vontade de tomar líquido [...]. O médico disse, agora não dá mais, agora vai ter que procurar um médico especializado. (E6, 43 anos)

Os sinais e sintomas apresentados pelos entrevistados podem representar inúmeras enfermidades, o que torna difícil uma assistência inicial especializada com foco na prevenção do agravamento da doença renal. Assim, ao apresentar a sintomatologia que levou à DRC, os pacientes podem ser expostos ao tratamento inadequado, gerando, inclusive, graves problemas ao seu estado de saúde.

\section{A relação com a máquina de hemodiálise}

A pessoa, ao se deparar com a real necessidade do tratamento hemodialítico, manifesta diferentes sentimentos. O entrevistado E1 relaciona-o com a dependência e o E5 com a difícil aceitabilidade, conforme as respectivas declarações: "Lutar e viver dependendo de uma máquina, eu fico pensando só nisso" (E1, 39 anos); "[...] O mais difícil foi começar aceitar a fazer e saber que não tem volta" (E5, 50 anos).

$\mathrm{Na}$ fala de E2 (66 anos), fica evidente o transtorno em ter que contar com a ajuda de filhos e netos. Ainda salienta o fato de não gostar de ocupar outras pessoas, preferindo estar ocupado:

Acho difícil fazer essa hemodiálise, ter que vir [...]. Eu acho assim, toma muito tempo da gente e eu tenho que estar ocupando a filha, neta [...]. Nunca gostava de ocupar ninguém, eu gostava que me ocupassem.

A entrevistada E3 (49 anos) faz essa relação com as atividades domésticas que necessita realizar após o término da sessão hemodialítica, podendo ser impossibilitada pelo estado de saúde que se 
encontra. Nesse caso, observa-se o desgaste físico provocado pela hemodiálise: A hemodiálise é a coisa mais difícil, porque tenho que chegar em casa e fazer as coisas [...]. Eu estou sentada aí, me dá uma dor de cabeça e fico olhando para as coisas e lá no outro dia que vou fazer, ou mais tarde que vou fazer minhas coisas.

A entrevistada E6 (43 anos) manifesta o sentimento de prisão acarretado pela hemodiálise. Percebe-se o afastamento na relação diária com o esposo, pois trabalhavam juntos, e com a doença e o tratamento, isso não é mais possível:

Agora eu me sinto presa. Não posso fazer o que gosto de fazer, que é trabalhar na lavoura com ele [marido]. [...] sabe que eu tinha a esperança que a hemodiálise, para mim, fosse um, dois dias [...] e o médico iria me dar alta. Essa esperança que eu tinha, aí foi passando o tempo e caí na realidade, não é tão simples.

Observa-se que a convivência com a máquina de hemodiálise, como finalidade para o tratamento da DRC, não é fácil. Deparar-se com a dependência da terapêutica estabelecida, ter que aceitar a situação imposta, precisar da ajuda de familiares, deixar as atividades rotineiras em segundo plano ou simplesmente se afastar delas, deixando de trabalhar com pessoas afetivas podem repercutir negativamente no estado psicológico do paciente.

\section{Quando faz a hemodiálise e a alteração da aparência física}

No dia da realização da hemodiálise, os entrevistados manifestaram a presença de sintomas advindos do tratamento. A maioria deles sendo subjetiva, como sonolência, sensação de mal-estar, pressão cefálica e fadiga, conforme relatos de E2 (66 anos), E3 (49 anos) e E4 (60 anos), respectivamente: "No dia que faço hemodiálise, me dá uma soneira, um mal-estar e eu não consigo ficar bem. Coisa engraçada, leva um tempão para a gente ficar bem"; "Tem dias que chego em casa, parece que vou morrer de tanta pressão que sinto na cabeça, parece que vai explodir [...]"; "A hemodiálise desgasta, tu cansas [...]".

Observam-se nessas falas, alguns dos possíveis efeitos sintomatológicos apresentados pelos entrevistados após as sessões de hemodiálise. Tais colocações podem levar ao abandono do tratamento, o que merece atenção por parte dos profissionais que o acompanham no serviço de nefrologia.

Em relação à alteração da aparência física, um dos aspectos salientados pelos entrevistados foi à imagem corporal alterada devido à existência da fístula arteriovenosa (FAV) ou do cateter de duplo-lúmen. Fato esse que leva a modificações na aparência, podendo alterar o estado psicológico do paciente.

Tais afirmações encontram correspondência no relato de E1 (39 anos): “A gente fica meio sestrosa por causa do braço. O meu braço [...], ele desenvolveu todo, é bem diferente dos outros".

Também demonstra isso a declaração de E4:
Achei que iria voltar ao normal [doença renal] [...], mas não me disseram que tinha que cortar o braço. Cheguei a andar com aquele negócio [cateter duplo-lúmen] no pescoço um bom tempo. Quando chegou para fazer a cirurgia do braço, aí sim, me apavorei. Fiz três vezes a cirurgia do braço. [...] A primeira que fiz parou de funcionar no outro dia. Depois fiz a segunda, mas ela começou a inchar, virou uma bola e no meio tinha um olho preto e estava querendo arrebentar. Aí o outro [...] começou incomodar também, perdi também e agora ele [médico] fez essa aqui. [...] Eu fiz em janeiro, mas dói na hora de botar aquelas agulhas. Botar e tirar, é um desespero. Não sei por que ela dói assim (E4, 60 anos)

Apesar da evolução da hemodiálise e dos acessos vasculares para proporcionar tratamento adequado, nota-se a repercussão que desempenham na vida do paciente. Observa-se na fala de E4 que, além de conviver com as constantes intervenções para a confecção da fístula arteriovenosa (FAV), o paciente sofre com o efeito doloroso durante a punção para a realização da hemodiálise prática corriqueira para os profissionais dos serviços de nefrologia que assistem os pacientes em hemodiálise, mas que gera desgaste e desconforto aos pacientes.

\section{Orientação sobre o cuidado à saúde $\mathrm{e} o$ autocuidado}

Nesta categoria, os entrevistados relataram a forma de orientação sobre o cuidado à saúde que recebem e a difícil realização do autocuidado. Nesse contexto, que permeia a DRC, há a necessidade em seguir restrições alimentares e hídricas, conforme os relatos:

A gente ganha um livrinho quando entra aqui. Eu anulei muita coisa de comer pelo livrinho, mas não chego seguir. Já segui no início e emagreci muito, tive que ir na nutricionista para ver [...]. A gente tem que seguir várias regras, alimentação e tudo. Não é muito fácil. Tem coisas que a gente quer comer e não pode. Lá em casa está proibido o tal do chocolate, porque não posso comer chocolate (E1, 39 anos).

Não dá para comer muito, mas precisa se alimentar. É que nem água, não dá para tomar um copão, mas dá para tomar. Às vezes me passo e como, mas não adianta, chego passando mal depois. [...] Urinar, eu não urino mais e para onde vai o liquido todo? Para o pulmão. Então não adianta exagerar na água (E4, 60 anos).

Eu como de tudo. Claro, não abuso. Me controlo, mas como de tudo [...]. Tem um livrinho que eles dão que explica tudo o que eu posso comer e as quantias, mas assim, tem que ser contado [...] (E5, 50 anos).

O que tenho que cuidar mais é a fístula (E6, 43 anos). 
Dos pacientes entrevistados, a maioria aborda o recebimento de normas a serem seguidas com relação aos cuidados da alimentação e do consumo de líquido. Todavia, apenas o E6 afirma que a necessidade de manter maior atenção é com a FAV. Esses fatores mostram a possível relação a ser estabelecida entre paciente e profissional de saúde como principal elemento de adesão ao tratamento da DRC.

\section{DISCUSSÃO}

Os rins são órgãos de primordial importância para o balanço sadio da química interna do corpo humano. Perante o surgimento da DRC, as funções renais se tornam comprometidas e verifica-se rápida ocorrência de graves anormalidades no volume ou na composição de líquidos corporais. Destarte, os rins são os únicos órgãos que podem ser substituídos, ainda que não perfeitamente por uma máquina ${ }^{2,15}$.

Os entrevistados deste estudo apontaram elementos característicos que indicaram a instalação da DRC, representados por enfermidades como a hipertensão arterial e o diabetes, que a literatura aponta como doenças responsáveis. Também existem outras, como: as glomerolonefrites, que causam inflamação nos rins; os rins policísticos, que são cistos grandes e numerosos, causando a destruição dos rins; as pielonefrites, que são infecções urinárias repetitivas, além de doenças congênitas ${ }^{16}$. Geralmente, os primeiros sintomas perceptíveis são edema na área dos olhos, das pernas e dos pés, diurese espumosa, anemia intensa, cansaço, sensação de fraqueza e aumento da pressão arterial ${ }^{6}$.

A realização do diagnóstico precoce da DRC é primordial ${ }^{6}$, mas lamentavelmente, a doença pode ser subdiagnosticada tardiamente ou tratada inadequadamente, gerando a perda de oportunidade para a implementação de sua prevenção devido à falta de conhecimento da definição e da classificação dos estágios da doença, assim como a não utilização de testes de diagnósticos simples para a avaliação funcional da doença ${ }^{1}$. Quando constatada sua instalação, inicia-se o tratamento para a substituição das funções renais. Nesse caso, a hemodiálise geralmente é a primeira terapia de escolha.

Como curiosidade a ser colocada, durante a Segunda Guerra Mundial, o médico holandês Willem Kolff foi o pioneiro na construção da máquina de hemodiálise. Desse modo, possibilitou iniciar o tratamento da DRC e incentivou vários estudos com foco na terapia da doença renal. Esse fato é considerado um dos maiores avanços da medicina, pois as máquinas de hemodiálise passaram por várias transformações, estando cada vez mais modernas e seguras. Os principais dispositivos desses equipamentos são: monitor de pressão e temperatura, filtros capilares, condutividade do dialisato, volume de ultrafiltração, detector de ar e fluxo de sangue. Possui sistema digitalizado (a dosagem das substâncias para a composição da solução é automática), alarmes e sensores (a máquina trava e toca o alarme perante qualquer substância estranha na corrente sanguínea), linha arteriovenosa (uma linha azul e outra vermelha) e cata bolhas para evitar que o ar entre no sangue. Há agulhas (esterilizadas e descartáveis que servem para dar passagem do sangue para a linha e para o capilar), banho do dialisador (a solução de diálise contém solutos que entram em equilíbrio com o sangue durante o processo dialítico), entre outros ${ }^{15}$.

Embora a hemodiálise seja vista de modo negativo, ela é um procedimento que consiste na circulação sanguínea extracorpórea, por meio do acesso vascular. É um tratamento doloroso, monótono e limitado, porém, indispensável para a manutenção da vida, uma vez que limpa e purifica o sangue, controla a pressão arterial e ajuda a manter o equilíbrio de substâncias químicas, como o sódio e o potássio. Geralmente, a queixa mais frequente entre os pacientes é a dependência da máquina, sendo esta uma condição vital de manutenção da vida, acarretando sofrimento e angústia ${ }^{8}$, conforme os dados expostos neste estudo.

Em oposição àqueles que apresentam pensamento negativo, uma questão apresentada nos resultados foi à esperança, conforme apontado pelo entrevistado E6. Parte dos pacientes que inicia a hemodiálise manifesta a esperança no retorno do funcionamento dos rins $^{3}$. Logo, essa ilusão é interrompida pela necessidade constante do tratamento e a constatação de que não há cura para a DRC.

Assim, conviver com a perda da liberdade e da capacidade produtiva para o trabalho são a realidade árdua vivenciada pelo pacientes com DRC. A apresentação de sinais e sintomas decorrentes da realização do tratamento e do esquema de hemodiálise (três vezes por semana por um período de quatro horas) impõe aos pacientes perdas significativas na saúde e no vigor físico ${ }^{15}$. Situações que foram apresentadas pelos entrevistados deste estudo, manifestadas pela presença de sonolência, sensação de mal-estar, pressão cefálica e fadiga durante a realização da hemodiálise.

Além da sintomatologia apresentada, os pacientes precisam conviver com as alterações físicas. Como mencionado neste estudo, a FAV e o cateter de duplo-lúmen foram os que mais geraram repercussões negativas em suas vidas.

Com relação ao cateter de duplo-lúmen, um estudo realizado apontou que os pacientes que precisam de seu uso inicial para a realização da hemodiálise, após receberem o diagnóstico da DRC, sentem-se como um extraterrestre, mas com as anteninhas no pescoço. Há a vergonha ao andar na rua e frequentemente reclamam dos olhares curiosos ${ }^{3}$. Embora esse dispositivo seja citado neste estudo, as FAV são os acessos mais realizados para a efetivação do tratamento hemodialítico.

Salienta-se que a técnica cirúrgica da FAV foi criada por Cimino e Brescia, por meio de uma anastomose interna, sendo um grande achado no tratamento da DRC. Além do mais, a criação da fístula foi importante para o sucesso terapêutico dos pacientes renais crônicos, pois garante um fluxo de sangue maior no local da punção e é um acesso vascular permanente ${ }^{15}$.

Ademais, E4 mencionou a presença de dor ao ter puncionada a sua FAV. Assim, evidencia-se que a necessidade humana básica de conforto é comprometida em cada sessão hemodialítica, quando o paciente se submete a uma punção na fístula com uma agulha 
de grosso calibre, processo muito doloroso, entretanto, necessário para que haja a possibilidade da realização do tratamento ${ }^{5}$.

Mesmo que a hemodiálise seja o tratamento essencial para a DRC, todo o seu avanço tecnológico se torna inócuo se o paciente não for acompanhado com atenção, respeito, fornecimento de informações, bom atendimento, além de empatia com o sofrimento alheio ${ }^{15}$. Assim, conhecer o lado de quem sofre e teve o seu cotidiano transformado, tornando-se vulnerável, pode ser o caminho à construção de assistência mais individualizada, direcionada aos problemas específicos da pessoa enferma, reduzindo a sensação do "ser mais um no contexto dialítico"17.

Outra questão apresentada neste estudo foi o recebimento de orientação sobre o cuidado à saúde e o autocuidado a ser efetivado. Na presença da DRC e do tratamento hemodialítico, há a necessidade de mudar hábitos na alimentação: evitar o sal, a gordura e o excesso de líquidos ${ }^{6}$, como foi orientado aos pacientes deste estudo. Ainda, considera-se fundamental a persistência dos cuidados para manter a FAV em funcionamento, como ressaltou E6.

Nesse contexto, considera-se que a relação profissional/paciente pode ser permeada por fantasias, medos e expectativas. O paciente espera que os profissionais que o acompanham possam lhe ajudar a compreender e a esclarecer dúvidas. Essa pode ser uma relação de muita tensão, já que as ações dos profissionais são impregnadas de sentimentos que possivelmente sejam úteis ou prejudiciais ao doente ${ }^{8}$.

Também compete ao profissional estimular a adesão do paciente ao tratamento estabelecido. É preciso construir estratégias educativas destinadas ao seguimento da hemodiálise, encorajando-o a ter uma vida ativa ${ }^{5}$. Assim, a relação vincular estabelecida com a equipe de profissionais exerce importante papel que colabora para a melhor aderência do paciente à terapêutica estabelecida. $O$ vínculo formado parece colaborar ainda para a diminuição de sintomas psicológicos (alterações na memória, lentidão de pensamento, pensamentos conturbados e desconexos, tristeza, raiva, choro) na medida em que o paciente encontra apoio no enfrentamento da doença e no tratamento. É fundamental, então, que a equipe esteja preparada além do conhecimento técnico para lidar com os aspectos projetivos que são direcionados a ela ${ }^{3}$.

Nesse caso, destaca-se entre os profissionais da saúde a enfermagem, por possuir maior contato com os pacientes. Nesse sentido, o cuidado a ser ofertado àqueles que estão em hemodiálise requer sensibilidade e empatia para o reconhecimento dos principais problemas enfrentados na adesão ao tratamento. Quanto à relação com o enfermeiro, esse deve promover o conforto, ajudar o paciente a cooperar com o tratamento, e proporcionarlhe o conhecimento necessário sobre a DRC e sobre a terapêutica estabelecida, de modo a enfrentar a situação da doença e amenizar o nível de estresse existente ${ }^{5}$.

$\mathrm{O}$ apoio da enfermagem é primordial para esses pacientes durante o tratamento. Para tanto, é preciso que haja perfeita integração e treinamento entre os componentes da equipe, e dela com os demais profissionais de saúde. O enfermeiro nefrologista deve ser tolerante, solícito, sensível e simpático, compartilhando sentimentos, mantendo a humildade e a compaixão, para proporcionar aos pacientes com a DRC o conforto necessário para aceitar o tratamento ${ }^{15}$. Assim, ressalta-se a importância da implementação de estratégias que possam contribuir para que o paciente se torne cada vez mais participativo e atuante no seu tratamento, possibilitando sua autonomia e estimulando o cuidado de si como uma possibilidade para melhor adesão à hemodiálise e à promoção da qualidade de vida ${ }^{18}$.

Ainda para complementar a discussão deste estudo, duas pesquisas semelhantes ao tema foram realizadas. A primeira, publicada em 2012, realizou abordagem quantitativa com o objetivo de analisar a qualidade de vida dos que realizavam hemodiálise. Os resultados mostraram que o tratamento mantém a vida, alivia sintomas, previne complicações (impedindo a evolução da doença) e promove o bom relacionamento com a equipe. Entretanto, o mesmo interfere na qualidade de vida, assim como no trabalho e na função físico-emocional ${ }^{19}$. A segunda pesquisa foi divulgada em 2015 e visou descrever as representações sociais de pessoas com DRC em hemodiálise sobre o processo de adoecimento, realizando uma investigação qualitativa e descritiva. As categorias formadas a partir da análise mostraram que a representação de adoecimento revelou diferença e interrupção dos projetos de vida, e a hemodiálise expressou perda de liberdade, prisão e estigma ${ }^{20}$.

No contexto vivenciado pelos entrevistados, é fundamental o apoio dos profissionais de saúde para a construção de uma relação harmoniosa, com vistas a promover orientações sobre adesão ao tratamento, além de cuidados específicos que os pacientes precisam manter com a sua saúde para o benefício do resultado da terapêutica estabelecida. Ademais, destaca-se a atuação da equipe de enfermagem, que por ser a profissão que possui como objeto de trabalho o cuidado e por estar mais próxima do paciente, poderá estimular o exercício da autonomia e do autocuidado em busca de melhor qualidade de vida.

Considera-se que este estudo permitiu conhecer a relação dos pacientes renais crônicos com a hemodiálise, embora tenha havido uma pequena amostra de participantes. Nesse sentido, a experiência da instalação da DRC, a dependência da terapêutica estabelecida e a relação com as normas de tratamento para o cuidado à saúde mostraram efeitos negativos sobre os pacientes, uma vez que se deparam com a dependência de suporte tecnológico especializado para a manutenção da vida.

Dessa forma, a compreensão das vivências dos pacientes em hemodiálise poderá remeter à importância de buscar cuidados singulares, pois o doente renal crônico pode apresentar dificuldades de enfretamento perante as restrições necessárias. Assim, espera-se que este estudo possa contribuir para a construção de novas pesquisas, promovendo reflexões e discussões com pauta na vivência do paciente com a doença renal e a relação que estabelece com a hemodiálise, no intuito de promover adequada intervenção para a melhora da qualidade de vida, amenizando o sofrimento vivenciado. 


\section{REFERÊNCIAS}

1. Bastos MG, Bregman R, Kirsztajn GM. Doença renal crônica: frequente e grave, mas também prevenível e tratável. Rev Assoc Med Bras. 2010;56(2):248-53

http://dx.doi.org/10.1590/S0104-42302010000200028

2. Medeiros AJS, Medeiros EMD. A assistência de enfermagem prestada no tratamento hemodialítico promovido junto ao portador de insuficiência renal crônica - uma revisão de literatura. REBES. 2013;3(2):13-7.

3. Nascimento FAF. Uma contribuição às reflexões sobre os aspectos emocionais e o papel do psicólogo na Hemodiálise. Rev SBPH. 2013;16(1):70-87.

4. Siviero P, Machado CJ, Rodrigues RN. Doença renal crônica: um agravo de proporções crescentes na população brasileira. Belo Horizonte: UFMG/CEDEPLAR; 2013.

5. Madeiro AC, Machado PDLC, Bonfim IM, Braqueais AR, Lima FET. Adesão de portadores de insuficiência renal crônica ao tratamento de hemodiálise. Acta Paul Enferm. 2010;23(4):546-51. http://dx.doi.org/10.1590/S0103-21002010000400016

6. Silva AS, Silveira RS, Fernandes GFM, Lunardi VL, Backes VMS Percepções e mudanças na qualidade de vida de pacientes submetidos à hemodiálise. Rev Bras Enferm. 2011;64(5):839-44. http://dx.doi.org/10.1590/S0034-71672011000500006

7. Frazão CMFQ, Ramos VP, Lira ALBC. Qualidade de vida de pacientes submetidos a hemodiálise. Rev Enferm UERJ. 2011;19(4):577-82.

8. Freitas PPW, Cosmo M. Atuação do psicólogo em hemodiálise. Rev SBPH. 2010;13(1):19-32.

9. Ribeiro CDS, Alencar CSM, Feitosa MCD, Mesquita MASB Percepção do portador de doença renal crônica sobre o tratamento hemodialítico. Rev Interd. 2013;6(3):36-44

10. Figueiredo AEPL. Doença renal crônica e estado nutricional. Sci Med. 2014;24(1):4-5.

11. Fontanella BJB, Luchesi BM, Saidel MGB, Ricas J, Turato ER, Melo DG. Amostragem em pesquisas qualitativas: proposta de procedimentos para constatar saturação teórica. Cad Saúde Pública. 2011;27(2):389-94

http://dx.doi.org/10.1590/S0102-311X2011000200020

12. Minayo MCS. O desafio do conhecimento: pesquisa qualitativa em saúde. $12^{a}$ ed. São Paulo: Hucitec-Abrasco; 2010.

13. Brasil. Ministério da Saúde. Conselho Nacional de Saúde. Resolução $n^{\circ} 196$ de 10 de outubro de 1996: Aprova diretrizes e normas regulamentadoras de pesquisas envolvendo seres humanos. Brasília: 1996.

14. Conselho Federal de Enfermagem (COFEN). Código de Ética dos Profissionais de Enfermagem. Resolução COFEN 311/2007. Rio de Janeiro; 2007

15. Xavier AS, Oliveira AKR, Brasileiro ME. Evolução histórica da hemodiálise e dos acessos vasculares para a assistência ao doente renal crônico. Disponível em: http://www.ceen.com.br/ revistaeletronica. Acesso em: 14 jun. 2015.

16. Mascarenhas CHM, Reis LA, Lyra JE, Peixoto AV, Teles MS Insuficiência renal crônica: caracterização sociodemográfica e de saúde de pacientes em tratamento hemodialítico no município de Jequié/BA. Rev Espaço Saúde. 2010;12(1):30-7.

17. Salati MI, Hossne WS, Pessini L. Vulnerabilidade referida pelos pacientes renais crônicos - considerações bioéticas. Rev Bioethikos. 2011;5(4):434-42.

18. Roso CC, Beuter M, Jacobi CS, Silva CT, Perrando MS, Bruinsma JL. Progressão da insuficiência renal crônica: percepções de pessoas em pré-diálise. Rev Enferm UFSM. 2013;3(Esp.):581-8. http://dx.doi.org/10.5902/2179769211020

19. Patat CL, Kirchner RM, Guido LA, Barbosa DA. Análise da qualidade de vida de usuários em hemodiálises. Enferm Glob. 2012;(27):66-76.

20. Campos CGP, Mantovani MF, Nascimento MEB, Cassi CC Representações sociais sobre o adoecimento de pessoas com doença renal crônica. Rev Gaúcha Enferm. 2015;36(2):106-12. http://dx.doi.org/10.1590/1983-1447.2015.02.48183 